\title{
THE EFFECTIVENESS OF PROPOLIS FLUORIDE APPLICATION IN INHIBITING DENTAL CARIES ACTIVITY IN SCHOOL CHILDREN AGE 6-9 YEARS OLD
}

\author{
RISQA RINA DARWITA*, ANDALINA RHUKUL FINISHA, HARDIATI NUR WAHYUNI, SALSABILA GHINA, \\ RAJIV MUHAMMAD, ANDY SATYANEGARA, FEBRIANA SETIAWATI, MELISSA ADIATMAN
}

Department of Dental Public Health and Preventive Dentistry, Faculty of Dentistry, Universitas Indonesia, Jakarta, Indonesia. Email: risqarina2004@yahoo.com

Received: 16 September 2017, Revised and Accepted: 3 October 2017

ABSTRACT

Objective: To obtain the effectiveness of propolis fluoride application in inhibiting dental caries activity.

Methods: The study was included 170 children aged 6-9 years old with active dentinal carries surface was 532 tooth surfaces, all of 532 tooth surface will applicate use propolis fluoride in school children at primary school SD Kukusan. Evaluation of the amount of dentinal caries lesion that has been arrested was conducted after 1 month, 2 months, and 4 months after topical application.

Results: After propolis fluoride applicated shows, that the activated process caries of dentinal caries lesion after 1 month was found in 104 tooth surfaces, 2 months were 115 tooth surfaces, and after 4 months evaluated were found significant increase to be 226 tooth surfaces on dentinal caries activated from $2^{\text {nd }}$ to $4^{\text {th }}$ month after application propolis fluoride $(\mathrm{p}<0.01)$. The percentages of arrested caries in, respectively, for $1^{\text {st }}$ month after the application is $99.80 \%, 2^{\text {nd }}$ month application is $78.32 \%$, and in the $4^{\text {th }}$ month is $57.52 \%$ while the score plaque of school children was decline significantly until $36.5 \%(\mathrm{p}<0.05)$ after 4 months intervention by tooth brushing every week at school.

Conclusion: The application of propolis fluoride is effective in inhibiting dentinal caries lesion activity, has the advantage of making no black discoloration to the teeth.

Keywords: Dentinal caries, Arrested caries, Propolis fluoride, School children

(c) 2017 The Authors. Published by Innovare Academic Sciences Pvt Ltd. This is an open access article under the CC BY license (http://creativecommons. org/licenses/by/4. 0/) DOI: http://dx.doi.org/10.22159/ijap.2017.v9s2.01

\section{INTRODUCTION}

Nowadays childhood dental caries is still a considerable health problem. According to the WHO, at the end of 2006, the incidence of dental caries in school-age children was about $60-90 \%$ [1]. The centers of disease control and prevention of United States reported the prevalence of early childhood caries (ECC) reached $28 \%$ of all toddlers and preschoolers in the U.S. and that almost half of the number of U.S. children had the ECC before entering kindergarten [2]. A comprehensive review of studies in Europe, Africa, Middle East, and North America also revealed the prevalence of childhood dental caries reached $70 \%$ and the highest prevalence was found in Africa and Southeast Asia [3-5].

A research in Jakarta in 2007 showed the prevalence of ECC in children under 3 years of age was $52.7 \%$ with def-t index 2.85 [6]. A research conducted in several private kindergartens in Jakarta showed the prevalence of dental caries by $59.5 \%$. Research on children aged 5 years old in Jabodetabek in 2014 showed the prevalence of dental caries by $90 \%$ with average def- $t$ index 7.54 and average of decay index 6.84 [7]. From a research conducted in DKI Jakarta in 2007, the prevalence of ECC in West Jakarta was 53\% with an average def-t 2.51 [8]. All of the data onto indicate that childhood dental caries still continues to be the main problem in children. This high prevalence of childhood dental caries is not compensated by dental treatment. According to the report of Ministry on Health on basic research of health 2013 , at group aged 1-4 years old, there were $10.4 \%$ children who had dental problems, yet only $25.8 \%$ who received treatment. While in the group aged 5-9 years old, there were $28.9 \%$ children who had dental problems, but only $35.1 \%$ who had received treatment. The treatments only included tooth extraction/filling/dental surgery [8].

The school-age children group is one of the groups that are prone to dental caries. The high cost, limited public access to dental care and the difficulty of treating dental caries in children that lack of cooperative behavior becomes the reasons of why management of childhood dental caries is still not adequate, and it needs the amount of time and serious, complex attention in treating it [9]. Besides, deciduous teeth are more susceptible to dental caries due to the structure and morphology which are different from the permanent teeth. Deciduous teeth contain more organic materials and water, but the amount of minerals is less than the permanent teeth, and the thickness of the enamel is only half of the permanent teeth [10].

Management and prevention efforts of dental caries are continuously performed, including research on the development of materials that are able to prevent the occurrence of dental caries. In the old way, dental caries was treated with restoration approach that required a complete dental equipment and trained operators and was relatively expensive. In the past few years, the treatment of dental caries starts to switch to minimally invasive techniques, including the theory of caries lesions remineralization and the treatment of arrested caries [11-16].

Among the available methods, topical application of silver diamine fluoride (SDF) offers effective, easy, and cheap alternative compared to the old method of high-cost restoration in preventing dental caries in children so that it can be recommended as a method to resolve the epidemic of childhood dental caries in Indonesia [17].

Topical application of SDF is proved to be effective in inhibiting the activity of dental caries against deciduous teeth and has been widely used in Australia, Japan, and Brazil. SDF is a material that can reduce demineralization of tooth structure due to dental caries and inhibit the growth of cariogenic multispecies biofilm. Practical application and affordability of dental caries treatment using SDF have gained a lot of 
attention recently. However, the concern is that the topical application of SDF contains silver which makes the surface of the treated tooth blackened and incites the uncomfortable taste of metal in children's mouths [17]. Researchers suggest that the SDF can prevent and arrest caries activity in deciduous teeth and root caries in permanent teeth. Recent in vivo study indicates that SDF is more effective as an anticariogenic than as a topical application of fluoride [17]. Annual SDF application can be one of the great solutions to prevent caries. As well as by increasing the frequency of SDF applications for every 6 months can improve the quality of inhibiting dentinal caries in deciduous teeth.

Researchers on the SDF have been started in Indonesia. In August 2013, the SDF application was given in Kindergarten and Early Childhood Education Programs in Serpong. The results of the 3 months evaluation were only a few presences of secondary dental caries found on cavities that were already smeared by SDF than dental caries that were not smeared by SDF. This circumstance was because of the unmaintained oral hygiene. The absence of secondary dental caries on teeth that were smeared by SDF proved that SDF was effective against inhibiting dental caries in deciduous teeth after 3 months of application [17].

New alternative to dental caries prevention is the development of natural materials like Propolis Fluoride. The selection of naturalbased medicines is based on the fact that the side effects of traditional medicine are lesser than the chemical or synthetic drugs [14]. In dentistry, propolis has been used to treat aphthous ulcers, candidiasis, gingivitis, periodontitis, and pulpitis $[15,16]$. In addition, some studies mentioned that propolis can also be used as an alternative material to prevent the occurrence of dental caries [13-16].

The main content of propolis is flavonoids. In vitro and in vivo study results show the very diverse biological and pharmacological activity of flavonoids compounds, one of the compounds has antibacterial activity against Gram-positive bacteria including Streptococcus mutans [13-16]. Flavonoids can inhibit the growth of bacteria by damaging the permeability of the cell wall, microsome, and lysosome of the bacteria as a result of the interaction between flavonoids and bacterium DNA [14]. In research conducted by Parolia et al. (2014), the evaluation of the influence of propolis against $S$. mutants viability, glucosyltransferases (GTFs) activities, and the formation of dental caries in rats showed that propolis has the potential to be an anticaries agent [14]. The result of in vitro study had been carried out to evaluate the influence of the combination of propolis and natrium fluoride in rats, summed up that the apigenin and tt-farnesol compounds could significantly reduce the virulence of $S$. mutans, which could increase the cariostatic effect of fluoride. The quantity of extracellular glucan in the biofilm with $S$. mutants was reduced. The combination of propolis and fluoride can be a potential alternative to be the standard chemical agents used in the prevention cariogenic process [16].

Some researchers have been conducted to develop propolis in various forms as anticaries agent in Indonesia, including propolis candy and propolis toothpaste $[13,15,16]$. The results of the study showed that Propolis candy was proved to be able to lower the amount of $S$. mutants colony in dental caries and free dental caries individuals after 7 days consumption $[15,16]$. The decrease in the average number of $S$. mutants and $S$. sobrinus occurred shortly after using propolis toothpaste [16]. The results of propolis fluoride with topical application research also showed that propolis fluoride was proved to have cariogenic bacteria growth inhibition power of approximately $78 \%$ and could remineralize the surface of the tooth enamel [16]. Thus, the further research was to evaluate regarding the effectiveness of propolis fluoride in preventing and arresting dental caries in deciduous teeth.

\section{METHODS}

This research is an experimental research study by administering the community intervention (Community Trial). The subject of the research was the students age 6-9 years old with similar characteristics, totalling 170 students with active dentinal caries surface were 532 tooth surfaces in primary school Kukusan in Depok city.

\section{Procedures}

In the beginning, submission of the feasibility of ethics to The Ethics Commission of Faculty of Dentistry University of Indonesia, No.66/ Ethical Approval/FKGUI/VIII/2016, was performed. After obtaining permissions, socialization of the program was performed in the primary school of Kukusan, Depok city. Following that, calibration and training for the oral examiners were performed by a fresh graduate dentist to minimize the occurrence of variance between inintering oral examinations, using kappa at every stage of the examination from the baseline stage until 4 months follow-up.

Before the examination education to the parents was conducted. All the examination procedures were explained including benefits, mechanisms, advantages, and disadvantages of the caries prevention materials as well as things to do and not to do, and the impact on dental caries if not treated. After the mothers understood and were willing to participate, then they signed informed consents and filled the questionnaires. The questionnaires included data onto the child's name, age, place/date of birth, gender, teeth cleaning habits, involvement of parents when the child's brushing teeth, usage of fluoride toothpaste, information of dental visit and examination, and eating and drinking habits, such as milk bottles feeding, cariogenic snacks consumption, and other information ranging from family status, economic status of the parents, the level of education of the parents, and the people closest to the children that sit them. The questionnaire was adapted to the similar study and calibration had been performed. It was also added with questions about the effects after propolis fluoride application, for example, sore sensation or irritation of the gingiva surrounding the treated teeth.

After that, examination of the teeth and oral cavities to all students was conducted to get DMF-S and plaque index on all groups of kindergarten students. Then, all children were treated with propolis fluoride application for the entire surfaces of the teeth with dentinal caries, propolis fluoride was applied using a microbrush, all children that had been treated with propolis fluoride application were instructed not to eat and drink for $30 \mathrm{~min}$ and all the students were instructed to maintain oral health by brushing teeth twice a day, morning after breakfast and at night before going to bed with a toothbrush and toothpaste that contains fluoride.

The evaluation was made after the $1^{\text {st }}$ month, $2^{\text {nd }}$ month, and $4^{\text {th }}$ month, the number of active caries, arrested caries, DMF-S, and plaque index were also recorded.

\section{RESULTS}

Table 1 summarizes that the mean DMFT score of school children was high $(9.98 \pm 0.74)$, and follows by mean of score decay was high too $(9.72 \pm 0.73)$.

After application of materials that can inhibit dental caries activity to the tooth surfaces, intraoral status of the respondents was re-examined after the $1^{\text {st }}$ month, $2^{\text {nd }}$ month, and $4^{\text {th }}$ month after application.

As shown in Fig. 1, that the entire surfaces that were smeared with propolis fluoride became arrested caries by $100 \%$, then after 1 month re-examination after application there was noticeable in the number of activated dental caries was 104 surfaces dentinal caries in the $1^{\text {st }}$ month evaluation, then increase 115 surfaces dentinal caries in the $2^{\text {nd }}$ month evaluation, and increase significantly to be 226 surfaces dentinal caries after 4 months applications. There was significant decrease $(p<0.05)$ in the amount of tooth surfaces that experienced arrested dental caries after being smeared with propolis fluoride in the $1^{\text {st }}$ month and $4^{\text {th }}$ month of application. Meanwhile, the significance value to indicate that there is a significant increase in dentinal caries activated from $2^{\text {nd }}$ to $4^{\text {th }}$ month after application propolis fluoride $(\mathrm{p}<0.01)$. 
* Significance value indicates that there is a significant increase in dentinal caries activated from $2^{\text {nd }}$ to $4^{\text {th }}$ month after application $(\mathrm{p}<0.01)$.

Fig. 2 indicates that the score plaque of children was decline significantly until $36.5 \%(\mathrm{p}<0.05)$ after 4 months intervention by tooth brushing every week at school.

Fig. 3 indicates that after 4 months teeth brushing intervention in school children could change their dental health behavior. The dental health behavior of school children was $41.91 \%$ increase significantly after 4 months teeth brushing intervention

Table 2 summarizes there was a significant correlation between tooth brushing intervention, decreasing score plaque and dentinal caries activated process $(\mathrm{p}<0.01)$, which mean is a good dental health behavior will effecting the score plaque to be low, thus the lowest score plaque will effect to inhibiting the activation of dentinal caries process.

\section{DISCUSSION}

The result showed that the prevalence of childhood dental caries by $85.05 \%$ with a mean value of def-t 5.7 , which largely dominated by the decay component with mean value 5.13. If it is compared to the research in 2007, childhood dental caries prevalence in West Jakarta had increased from $53 \%$ and mean value of def-t 2.51 [9].

Caries prevalence in children aged 4-5 years on this research is moderate, according to the WHO (5-20\% free-caries). The prevalence of free dental caries is still far from the FDI global goals target, which targets $50 \%$ of children aged 5-6 years will be free caries in 2015 . Hence, that the program for oral health improvement in pre-school age children is needed. Based on the intraoral examination, it can be observed that there are tendencies toward certain tooth positions and tooth surfaces in the occurrence of dental caries. Childhood dental caries is most often experienced on the maxillary anterior and mandibular posterior. These results are consistent with Saravanan's research where the prevalence of dental caries in 5-year-old children was significantly higher on the mandibular posterior teeth and maxillary anterior teeth $[13,16]$.

Majority of the children (72.3\%) have dietary habits of consuming food or beverages between meals more than 2 times in a day which becomes one of the factors to cause the high prevalence of dental caries. Risk of dental caries increased due to the high consumption of sugary food and beverages especially in children who take it between meals, and on a

Table 1: Intraoral status of the respondents in the initial examination

\begin{tabular}{ll}
\hline Intraoral status & Mean \pm SD \\
\hline DMFT score & $9.98 \pm 0.74$ \\
Decay score & $9.72 \pm 0.73$ \\
\hline
\end{tabular}

SD: Standard deviation

Table 2: Correlation between dental health behavior, score plaque and dentinal caries activated process after 4 month tooth brushing intervention in school children age 6-9 years old

\begin{tabular}{|c|c|c|c|c|}
\hline \multirow[t]{3}{*}{ Oral condition } & \multicolumn{3}{|c|}{$\begin{array}{l}\text { Dental health behavior } \\
\text { Intervention (month) }\end{array}$} & \multirow[t]{3}{*}{$\mathbf{p}$} \\
\hline & \multicolumn{3}{|l|}{ Mean \pm SD } & \\
\hline & 1 & 2 & 4 & \\
\hline Plaque & $1.78 \pm 0.05$ & - & $1.13 \pm 0.04$ & 0.01 \\
\hline $\begin{array}{l}\text { Total number dentinal } \\
\text { decay surfaces applied } \\
\text { propolis fluoride }\end{array}$ & 104 & 115 & 226 & \\
\hline
\end{tabular}

toddler who especially drinks sugary milk before sleep and often do not clean the teeth or gargle with water thereafter [16].

Habits or behavior of the parents tends to consider oral health as their low priority. It leads them to rarely do dental visits or come merely when the children feel pain. It is shown by only $15.7 \%$ of the respondents that went to the dentists with no pain complain and only $22.8 \%$ that went to the dentist due to pain and dental caries of their children. These things become other contributing factors that cause the high prevalence of dental caries in children $[3,4]$

When propolis is applied to the dentin, it has the effect to block the dentinal tubules. It will form a stable layer on the surface of the dentin that is insoluble by water irrigation $[13,14]$. The dentin surface seems

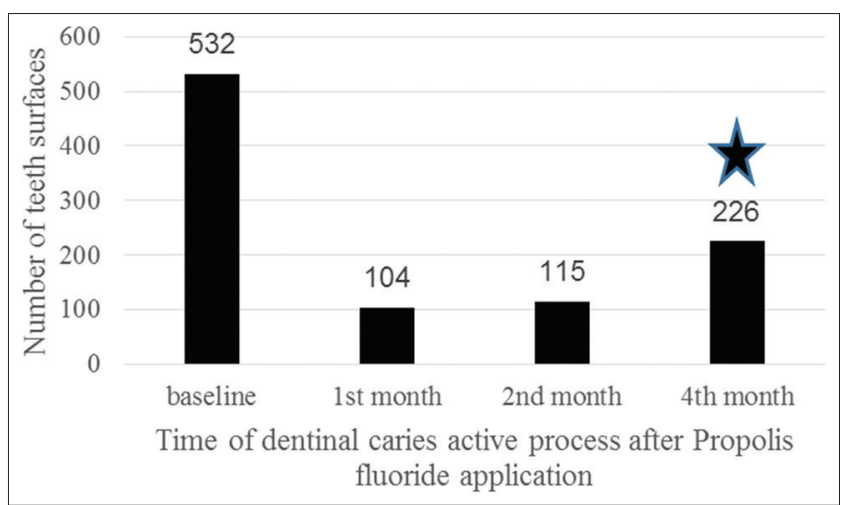

Fig. 1: Total number of arrested caries after application propolis fluoride from the $1^{\text {st }}$ to $4^{\text {th }}$ month

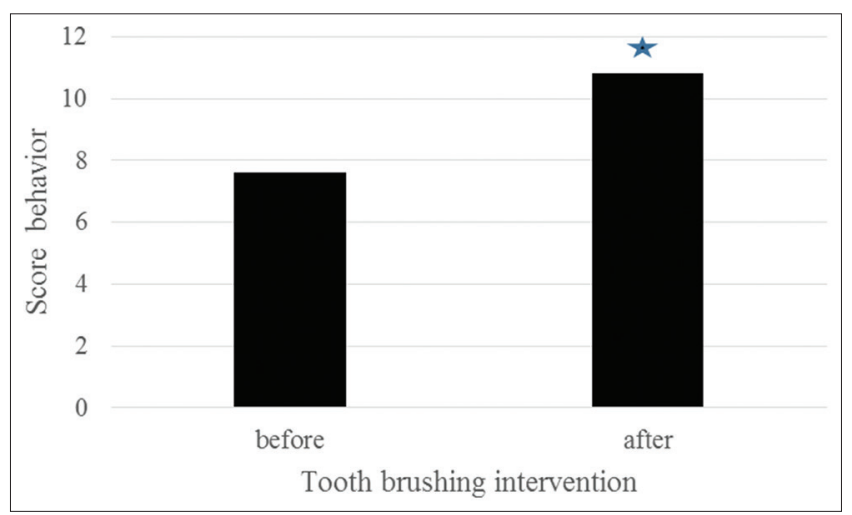

Fig. 2: The changes of dental health behavior of school children in 4 months

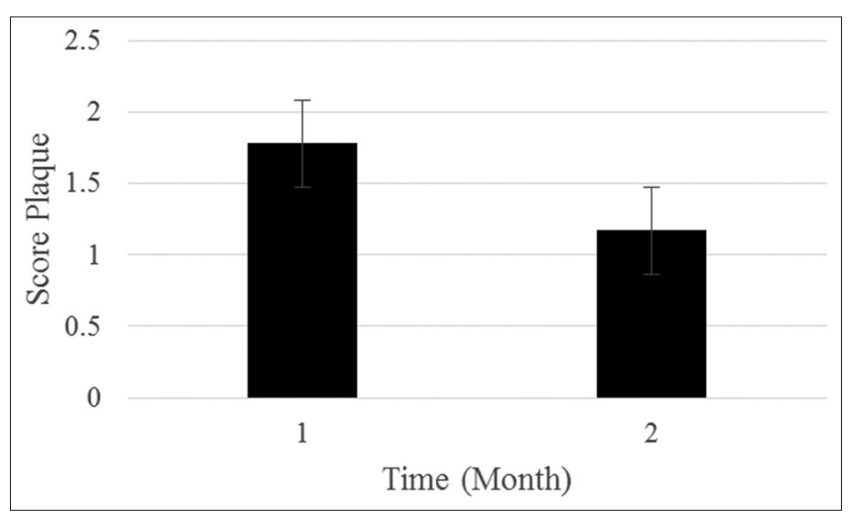

Fig. 3: The changes of score dental plaque of school children in 4 months 
to be covered by granular layers, and the dentinal tubules reduced its diameter [16]. Propolis fluoride is proved to remineralize the enamel surface of the tooth [16].

\section{Comparison of effectiveness between SDF and propolis fluoride application}

The percentage of the active dental caries that became arrested on Silver Diamine Flouride application was found more than in the propolis fluoride application. These shows that active dental caries that was smeared by Silver Diamine Fluoride and was more likely to become arrested compared to the propolis fluoride. Mechanism of SDF and propolis fluoride in inhibiting the dental caries activity is basically the same. Both of these materials have antibacterial properties, where antibacterial property on SDF is in the silver ion, while antibacterial property on propolis fluoride is from ethanol propolis extract.

Antibacterial properties on both of these materials work to inhibit the formation of biofilms by disrupting the enzyme activity of glucosyltransferase (GTF), which plays a role in the activity of glucan in the process of adhesion/bonding to the surface of the tooth for sucrose depending organisms $[9,10,12]$. GTF simplify the formation of the glucan alpha bond from sucrose which significantly will make the polysaccharides matrix. The collection of this polysaccharide matrix will create plaque. Disruption of this enzyme activity leads to decreased sugar synthesis and decreased polysaccharides matrix formation; thus the formation of plaques can be reduced [12]. On the other hand, fluoride content changes the hydroxyapatite to fluorapatite (Ca10 (P04)6F2) which is more resistant to demineralization in the acid environment. The formation of fluorapatite which is more resistant to the acidic environment and the limited cariogenic bacteria cause demineralization is replaced with remineralization and thus make caries arrested.

The difference in effectiveness between SDF and propolis fluoride is the difference of the formation of a more stable protective layer on SDF. When propolis fluoride is applied, the propolis content has the effect of causing the blocked dentinal tubules and forms a stable layer on the surface of dentin which is insoluble by water irrigation. $\mathrm{Ag}_{3} \mathrm{PO}^{4}$ deposition on SDF also forms a protective layer over the surface of the teeth, which is also not easily dissolved. The layer does not only cover but also act as a reservoir of phosphoric ion that is instrumental in the formation of fluorapatite [17].

In addition, the coverage also protects the tooth from losing calcium and phosphate in caries lesions. SDF also works to protect the type I collagen which is the structure that binds the hydroxyapatite from degradation when demineralization of the dentin occurs [17]. Decreased collagen damage in dentin and increased dentin rigidity after the application of SDF were observed. Meanwhile, antibacterial property on SDF is more powerful when compared to propolis fluoride. It was based on the greater percentage of the decreased number of mutans colony on SDF application than on propolis fluoride application.

The levels of fluoride on SDF are also greater than propolis fluoride. According to Mei, 38\% SDF contains approximately 44,800 ppm fluoride [17]. While propolis fluoride has levels of fluoride approximately $21,000 \mathrm{ppm}$ fluoride. The percentage of the arrested caries decreased coincided with the passage of time. After 1 month compared to 3 months evaluation of the application of SDF, there is a decrease in the percentage of arrested caries from $96.84 \%$ to $88.68 \%$. This supports several research that had been done that the application of SDF can be one good solution to prevent caries. As well as by increasing the frequency of application of SDF for every 6 months can improve the quality in arresting dentinal caries in deciduous teeth [17].

Meanwhile propolis fluoride, based on the decreased number of arrested caries from $81.78 \%$ ( 1 month evaluation) to $55.77 \%$ (3 months evaluation), reapplication can be recommended every 3 months to increase the effectiveness in arresting caries. Thus, the further research was to evaluate regarding the effectiveness of propolis fluoride in preventing and arresting dental caries in deciduous teeth. Moreover, the increased frequency to every 3 months application of propolis fluoride is due to the recommendation that in children with high risk of dental caries should receive topical application of fluoride more often [13-15]. Both of these materials can become alternative to manage dental caries in children who are less cooperative and at the location where lack of dental health professionals, instead of using conventional techniques with the restorative approach.

SDF indeed proved to have better effectiveness than propolis fluoride, but one of the weaknesses of the SDF is making the surface of the smeared teeth blackened. The superiority of propolis fluoride includes making no discoloration and does not cause a taste of metal in children's mouths. Moreover, because it is derived from natural ingredients so that it has lesser side effects and toxicity [17]. In addition, the production cost of propolis fluoride is cheaper, because the price of silver is more expensive than the propolis.

The position and the surface of the tooth also affect the occurrence of arrested caries. This is in line with the results of Zhi research who found that carries on the anterior teeth and the buccal/lingual surfaces have greater opportunities to be arrested. This is possible because the teeth and the surfaces are more easily cleaned in children. Topical application of SDF or propolis fluoride would be more effective in children with the habit of brushing teeth twice a day, regular dental visits, and rarely eat snacks.

\section{CONCLUSION}

Topical application of propolis fluoride is effective in discontinuing the progression of active dentinal caries surfaces to become arrested caries, and topical application of propolis fluoride is effective in inhibiting the dentinal caries activity. While topical application of propolis fluoride offers another advantage of making no black discoloration to the teeth. A good dental health behavior will effecting the score plaque to be low; thus the lowest score plaque will effect to inhibiting the activation of dentinal caries process. Therefore, if the children have a good oral hygiene will effect to inhibiting the activation of dentinal caries process, and the Propolis Retention in dentinal caries surface will be longer.

\section{ACKNOWLEDGMENT}

The research was granted by Directorate of Research and Community Engagement grant from University of Indonesia.

The publication of this manuscript is supported by Universitas Indonesia.

\section{REFERENCES}

1. Colak H, Dülgergil CT, Dalli M, Hamidi MM. Early childhood caries update: A review of causes, diagnoses, and treatments. J Nat Sci Biol Med 2013:4:29-38

2. Olatosi OO, Inem V, Sofola OO, Prakash P, Sote EO. The prevalence of early childhood caries and its associated risk factors among preschool children referred to a tertiary care institution. Niger J Clin Pract 2015;18:493-501.

3. Khanh LN, Ivey SL, Sokal-Gutierrez K, Barkan H, Ngo KM, Hoang HT, et al. Early childhood caries, mouth pain, and nutritional threats in vietnam. Am J Public Health 2015;105:2510-7.

4. Rina DR, Anton R, Mellisa A, Peter A. Peningkatan kesehatan gigi dan mulut balita melalui pendekatan tailored message. Dent Dent J 2013;17:15-20.

5. Adiatman M, Yuvana AL, Nasia AA, Rahardjo A, Maharani DA, Zhang S. Dental and periodontal status of 5 and 12 years old children in Jakarta and it's satellite cities. J Dent Indones 2016;23:5-9.

6. Kementrian Kesehatan RI. Laporan Hasil Riset Kesehatan Dasar 2013; 2014.

7. Rina DR, Mellisa A, Febriana S, Anton R, Peter A. The behavior change on brushing teeth of children by mothers using periodic dental health evaluation card. J Int Dent Med 2016;9:273-81.

8. Fung $\mathrm{MH}$, Wong $\mathrm{MC}$, Lo EC, Chu $\mathrm{CH}$. Arresting early childhood caries 
with silver diamine fluoride-a literature review. J Oral Hyg Health 2013;1:117.

9. Mehta A, Bhalla S. Assessing consequences of untreated carious lesions using pufa index among 5-6 years old school children in an urban Indian population. Indian J Dent Res 2014;25:150-3.

10. Contreras V, Toro MJ, Elías-Boneta AR, Encarnación-Burgos A. Effectiveness of silver diamine fluoride in caries prevention and arrest: A systematic literature review. Gen Dent 2017;65:22-9.

11. Ahuja V, Ahuja A. Apitherapy-a sweet approach to dental diseases. Part II: Propolis. J Acad Adv Dent Res 2011;2:1-8.

12. Rosmarie V, Nadine MW, Belibasakisc GN, Thomas A, Schmidline PR, Scragg $\mathrm{R}$, et al. Antibacterial efficacy of a propolis toothpaste and mouthrinse against a supragingival multispecies biofilm. Oral Health Prev Dent 2015;13:531-5.

13. Ozalp S, Tulunoglu O. SEM-EDX analysis of brushing abrasion of chitosan and propolis based toothpastes on sound and artificial carious primary enamel surfaces. Int J Paediatr Dent 2014;24:349-57.

14. Hongal S, Torwane NA, Goel P, Chandrashekar B. The effect of $30 \%$ ethanolic extract of Indian propolis on replica of human dentin compared against commercially available desensitizing agent: A methodological SEM study in vitro. Pharmacognosy Res 2014;6:113-9.

15. Mei ML, Chu CH, Lo EC, Samaranayake LP. Fluoride and silver concentrations of silver diammine fluoride solutions for dental use. Int J Paediatr Dent 2013;23:279-85.

16. Mei ML, Li QL, Chu CH, Yiu CK, Lo EC. The inhibitory effects of silver diamine fluoride at different concentrations on matrix metalloproteinases. Dent Mater 2012;28:903-8.

17. Zhi QH, Lo EC, Lin HC. Randomized clinical trial on effectiveness of silver diamine fluoride and glass ionomer in arresting dentine caries in preschool children. J Dent 2012;40:962-7. 